
\title{
$\angle S$ Research Square \\ Determinants of Birth Asphyxia At Public Hospitals in Ilu Aba Bor Zone Southwest, Ethiopia: A Case Control Study
}

\section{Tarekegn Fekede Wolde ( $\square$ fekedetarekegn88@gmail.com )}

Department of Nursing, College of Public Health and Medical Sciences, Mettu University, Oromia Region, Southwest Ethiopia https://orcid.org/0000-0003-2464-7151

Firomsa Bekele

Mettu University

Abeya Fufa

Meu: Mettu University

\section{Research}

Keywords: birth asphyxia, determinants, newborn, Ilu Abba Bora, public hospitals

Posted Date: October 29th, 2021

DOI: https://doi.org/10.21203/rs.3.rs-1007121/v1

License: (9) (1) This work is licensed under a Creative Commons Attribution 4.0 International License. Read Full License 


\section{Abstract}

Despite birth asphyxia is one of the important causes of morbidity and mortality in newborn; its determinants were not investigated according to local context especially in this area. Thus, this study aims to investigate the determinants of birth asphyxia at Illu Aba Bor zone public health facilities.

Study Design: An Institution based a case-control study.

Methods: Systematic random sampling technique was used to select 308 (103 cases and 205 controls) newborn. Data were collected using checklist for record review \& interviewer administered questionnaire and entered in to Epi-data version 3.1 and analyzed using SPSS version 24. Variables with P-value $<0.25$ were taken to multi-variable regression. Backward likelihood ratio with 0.1 probability removal was used to develop the model. Collinearity, goodness fit of final model using Hosmer Lemeshow test considering good fit at P-value $\geq$ 0.05 (0.208), omnibus likelihood test $<0.05(0.000)$ and model classification of accuracy $(77.9 \%)$ were checked. Odds Ratio estimated with $95 \% \mathrm{Cl}$ was used to show strength of association and P-value $<0.05$ was used to declare statistical significance.

Results: A total of 308 (103 cases and 205 controls) mothers of newborns were interviewed yielding a response rate of $100 \%$. The mean age ( \pm Standard deviation) of mothers for the cases and the controls were 25.97 (SD: \pm 4.47 ) and 25.52(SD: \pm 4.17 ), respectively. Being not educated (non-formal education) [AOR=2.44; (95\% Cl:1.37, 4.34)], having antenatal care follow up $<4$ [AOR=2.30; (95\% Cl:1.17, 4.53)], Prolonged duration of labour [AOR=4.12; (95\% Cl:1.78, 9.50)], non-cephalic fetal presentation [AOR=4.35; (95\% Cl:1.77, 10.67)] and being primi-gravida $[A O R=2.14 ;(95 \% \mathrm{Cl}: 1.20,3.83)]$ were the predictors of birth asphyxia. Whereas, neonatal factor such as: being preterm [AOR=5.77; (I95\%:2.62, 12.69)] and low birth weight [AOR=4.43; $(95 \% \mathrm{Cl}: 1.94,10.13)]$ were also the predictors of birth asphyxia

Conclusion: Predictors were maternal and newborn related characteristics. Therefore, interventions focusing in this area should give priority for these identified determinants.

\section{Introduction}

Birth asphyxia is a most common and serious neonatal health problem globally and it significantly contributes to neonatal morbidity[1]. It can be defined as level of neonatal breathing at extramural babies per minute age or intramural babies, birth Asphyxia-Apgar score of less than 7 at 5 minute of age[2]. Moreover, globally, by 2017 alone, 5.4 million children died before reaching their fifth birthday and 2.5 million of those children died in the first month of life, of which $23 \%$ of all deaths were from Birth asphyxia which is the fifth largest cause of under 5years mortality [3].

In addition to this, WHO, reports indicate that, birth asphyxia is the third major causes of neonatal deaths after infection and preterm birth which accounts about $23 \%$ in developing country mainly in Asia $40 \%$ and $34 \%$ in sub-Saharan Africa [4]. For example, in sub Saharan country Ethiopia reached its MDG4 child mortality goal despite to this neonatal mortality remains high [5] which was mainly contributed from birth asphyxia (31.6\%) [5]. Furthermore, out of worldwide neonatal deaths, $24 \%$ were due to birth asphyxia with serious neurological sequels [3],[6], [7] and [8]. 
Even though a number of contributing factors to birth asphyxia existed, the main factors thought to be categorized into Maternal, fetal and materno-fetal factors [3]. Of maternal risk factors: age, educational status and marital status [3, 9-15]. In addition to maternal socio-demographic past maternal obstetric factors like No or less ANC follow up [15] ,[11, 12] being primparous [16],[17], child loss [16] were also determinants of birth asphyxia, Moreover, meconium stained amniotic fluid [18],[19] and other labour complications [20],[21] and fetal malpresentation \& low birth weight were risk factors for birth asphyxia.

Despite high attributes of birth asphyxia to neonatal death, most of the risk factors were preventable and treatable [5], [15]. Along with this, most countries were developed guidelines to treat neonatal asphyxia including Ethiopia [22]. However, neonatal death is still high as it quoted 'world is failing new-born's by UNCIEF (21) \& it's challenging to achieve sustainable development goals (SDGs) 12per 1000 live births by 2030[9]. So, to reduce the impact of birth asphyxia on neonatal morbidity and mortality, it needs further different study in diverse settings including Ethiopia. Hence, studies are required to identify the determinants of birth asphyxia to avert the problem. Therefore, this study aims to identify the determinants of birth asphyxia especially in study area.

\section{Methods}

\section{Study Design and Setting}

A facility based case-control study was used in llu Abba Bora zone public hospitals. Ilu Aba Bora is bounded by East wollega zone from the North, on the south southern nation and nationalities, on the west by Kelem Wollega, on the Northwest by west wollega and on the east by east wollega zone and the zone is more than $600 \mathrm{~km}$ away from the capital of Ethiopia, Addis Ababa. The zone comprises about a total population of $1,197,156$ of whom 58,7134 are men and 610,022 women; with an area of $16,555.36$ square kilometers, llu Abba Bora has a population density of 72.31. The zone has two governmental hospitals.

\section{Study participants}

All term newborns during the study period were sorted for eligibility for the study. While such cases were not detected, the authors aimed exclude newborns with congenital anomalies and birth defects. In this study, subjects were classified into cases and controls. Newborns diagnosed with APGAR scores of $<7$ at 5 minutes by physician were defined as having birth asphyxia and those newborns with APGAR scores of $>7$ at 5 minutes were considered as not having birth asphyxia

\section{Sampling and sampling technique}

Sample size was determined by double population proportion formula, using Epi- info version 7 from factors reviewed by considering $95 \% \mathrm{Cl}, 80 \%$ power, $1: 2$ case to control ratio, Odds Ratio $=2.21$ which is the ratio of odds of cases among neonates with birth asphyxia to odds of controls among neonates free of birth asphyxia; proportion of controls $22.7 \%$ and proportion of cases as $39.3 \%$ and the final sample size was 308(103 cases and 105 controls) after adding $5 \%$ non-respondent rate. Systematic random sampling was used for all delivered neonates in the study as a sampling frame. By taking a monthly delivery report from the hospital and 
considering a $15.6 \%$ proportion of asphyxiated newborns. Every other asphyxiated baby was selected as a case, while every $3^{\text {th }}$ non-asphyxiated newborn was enrolled as a control.

\section{Data collection tool and procedure}

Primary and secondary data (record review) were used. A pretested structured questionnaire was used to collect data which was prepared in English and translated into local language 'Afan Oromo' then translated back into English for consistency by linguist. Data were gathered by trained BSc Nurses' after cases were confirmed by physicians (birth asphyxia) cases and controls were recorded by identification number. Then, cases and controls were differentiated and data were collected by reviewing delivery registration book/patient index card and the study participants were interviewed.

\section{Data Quality and Analysis}

Data were collected by trained health professionals and cleaned, coded and entered into Epi-data version 3.1 and then transported into SPSS version 24 for analysis. Frequencies and cross tabulations were used to summarize descriptive statistics. The association between birth asphyxia and each covariate was assessed first by bivariate logistic regression to identify candidate variable for final model. Variables with P-value $<0.25$ were taken to multi-variable regression. Backward likelihood ratio with 0.1 probability removal was used to develop the model. Collinearity diagnosis was checked. Goodness fit of the final model was checked using Hosmer Lemeshow test of goodness fit considering good fit at P-value $\geq 0.05$ (0.208), omnibus likelihood test $<0.05(0.000)$ and model classification of accuracy was checked (77.9\%). Odds Ratio estimated with $95 \% \mathrm{Cl}$ was used to show strength of association and P-value $<0.05$ was used to declare statistical significance.

\section{Results}

\section{Socio-demographic characteristics}

A total of 308 (103 cases and 205 controls) participants were involved in this study with a response rate of $100 \%$. The mean age ( \pm Standard deviation) of mothers for the cases and the controls were 25.97 (SD: \pm 4.47 ) and 25.52(SD: \pm 4.17$)$, respectively. Concerning educational status, $74(71.8 \%)$ mothers of the cases and $171(83.4 \%)$ controls were educated (had formal education). Seventy-five (72.5\%) of mothers for the cases and $143(69.8 \%)$ controls were married. Regarding occupation, $85(82.5 \%)$ mothers of the cases and $158(77.1 \%)$ controls were government employee (Table 1)

\section{Past Obstetrics related characteristics}

Connected the characteristics of past obstetrics history, twenty-eight (27.2\%) mothers of the cases and ninetyone $(44.4 \%)$ controls were prim parous. Fifteen (14.6\%) mothers of the cases and $16(7.8 \%)$ controls had history of miscarriage while $13(12.6 \%)$ mothers of the cases and 17 (8.3\%) controls had history of child loss, Regarding the frequency of antenatal care follow up, 84(81.6\%) mothers of the cases and $173(74.4 \%)$ of controls had antenatal care follow up more than four times (Table 2)

\section{Intrapartum related characteristics}


From the study participants, 20(19.4\%) mothers of the cases and 13(6.4\%) controls developed prolonged labor and $83(80.6 \%)$ mothers of the cases and 192(93.7\%) controls gave birth through spontaneous vaginal delivery. Concerning rupture of membrane, $10(9.7 \%)$ mothers of the cases and $11(5.4 \%)$ controls had prolonged rupture of membrane whereas $17(16.5 \%)$ mothers of the cases and $11(4.5 \%)$ controls had non-cephalic presentation. Ninety-eight mothers of the cases (95.1\%) and 201 (98.1\%) controls had singleton baby (Table 3)

\section{Medical related characteristics}

Eleven $(10.7 \%)$ mothers of the cases and fourteen (6.8\%) controls had history of anemia during pregnancy. Nine $(8.7 \%)$ mothers of the cases and 4 (2.0\%) controls had history of hypertension, and $7(6.8 \%)$ mothers of the cases and $3(1.5 \%)$ controls had also history of diabetes mellitus during pregnancy (Table 4)

\section{Neonatal related characteristics}

Twenty-six (25.2\%) of the cases and 15 (7.3\%) of the controls had gestational age of less than 37 weeks (preterm) and $37(35.9 \%)$ of the cases and $93(45.4 \%)$ of the controls were females. Regarding weight of new born, $21(20.4 \%)$ of the cases and $14(6.8 \%)$ of the controls had birth weight less $2500 \mathrm{gm}$ (Table 5)

\section{Determinants of Birth Asphyxia}

In bivariate logistic regression analysis: maternal age, educational status, antenatal care, hypertension, duration of labor, prolonged rupture of membrane, fetal presentation, parity, gestational age at birth and newborn weight fulfilled the criteria and were potential candidates for the multiple logistic analysis.

In multi-variable logistic regression analysis: educational status of mothers, number of antenatal care follow up, duration of labor, fetal presentation, parity, gestational age and weight of newborn were significantly associated with birth asphyxia

The odds of developing birth asphyxia were more than two times higher in neonates whose mothers not had formal education than educated ones (AOR=2.44; [95\% Cl:1.37,4.34]). New-borns delivered from mothers who had antenatal care follow up less four times were 2.30 times higher to develop birth asphyxia than those whose mothers had greater than four times antenatal care follow up (AOR=2.30; [95\% Cl:1.17,4.53]). Newborns of mothers who had prolonged labour were 4.12 times more likely to develop birth asphyxia as compared to those with normal labour (AOR=4.12; [95\% Cl:1.78,9.49]). Babies born with non-cephalic presentation were 4.35 times more likely to develop birth asphyxia than their counterparts (AOR=4.35; [95\%Cl: 1.77, 10.67]). Neonates delivered from prim parous mothers were 2.14 times higher to develop birth asphyxia than multiparous $(A O R=2.14 ;[95 \% \mathrm{Cl}: 1.20,3.83])$. This study also revealed that newborns with low gestational age were 5.77 times more likely to develop birth asphyxia than their counterparts (AOR=5.77; [95\% $\mathrm{Cl}: 2.62,12.69])$. Low birth weight neonates were 4.43 times higher to develop birth asphyxia than normal one (AOR=4.43; [95\% $\mathrm{Cl}$ : 1.94 , 10.13]) (Table 6)

\section{Discussion}

The odds of developing birth asphyxia among neonates born from mothers of no formal education were 2.44 times higher than those born to mothers who had formal education. This finding is consistent with study done 
in Aksum [13], which revealed that mothers who not educated were more likely to develop birth asphyxia compared to those who were educated; Pakistan [19], Kenya [23], Nepal [24], Sweden [14] and Cameroon [10] where newborns who were born from mothers with no formal education had higher risk for birth asphyxia. This might be due to the non-educated mothers have poor socio-economic conditions associated with consequent malnutrition, frequent pregnancies and also influence care seeking behaviors during antepartum period. However, the study in Gondar [25] and Malawi [13] were reported that educational status not associated with birth asphyxia. The difference in the finding could be due to sample sizes differences, observer and measurement bias.

Maternal age at delivery did not be significant with the birth asphyxia in this study. This suggests that pregnancy and labour in all age groups cannot predict the occurrence of birth asphyxia if effectively managed. This study finding is similar to the study findings in Gondar [25], Pakistan [15], Kenya [26] and Thailand [27], which reported that that maternal age was not determinant factor for birth asphyxia. Other study in Iraq [20] showed that estimation of young ( $\$ 18$ years) mothers were not associated with birth asphyxia. However, this findings is inconsistent with study conducted in Kenya [23] which reported that maternal age was significant risk factor to develop birth asphyxia. This conflict could be due to the different sample size used or the nature of setting where the study was conducted.

Number of antenatal care follow up was significantly associated with birth asphyxia that the odds of developing birth asphyxia among babies of mothers who had antenatal care follow up less than four times were 2.30 times higher as compared to those had more than four times antenatal care follow up. This finding is in line with study done in Rwanda [11], evidenced that who had not full antenatal follow up was associated with developing birth asphyxia. This could be described by the fact that antenatal care less than four (incomplete) affects the life and health of babies by providing integrated care, promoting healthy home practices, influencing care-seeking behavior, and referring women with pregnancy complications to a referral system.

In this study, neonates from mothers who had prolonged labor were 4.12 times more likely to develop birth asphyxia than those with normal labor. This finding is similar to studies done in Aksum[13], Gondar[25], Pakistan [15], and Rwanda [11] where the odds of developing birth asphyxia was higher among neonates of mothers who had prolonged duration of labor. Study from Kenya [23] also indicated that labour duration was another important risk factor of asphyxia. This might be cause of mother's pelvis is not adequate for her newborn's head to pass through, or does not have adequate contraction, or effacement of the cervix and the newborn is big [24]. Also it is clear that when labour is prolonged, there is a high probability for the fetus to become distressed and result to birth asphyxia. Study in Nigeria [21] also exposed that prolonged labour is associated with fetal and maternal exhaustion and also fetal distress which results in birth asphyxia.

Fetal presentation had significantly associated with birth asphyxia. This study found that neonates born with non-cephalic presentation were 4.35 times more likely to develop birth asphyxia than those with cephalic presentation. This study similar with study done in Pakistan [28] and Iraq [29] as fetal malpresentation was significantly associated with in occurrence of birth asphyxia. This could be due to the fact that, the fetus which experiences oxygen deprivation by change fetal heart rate, decreased fetal movements and increase meconium in the amniotic fluid. Fetal malpresentation increase the risk of numerous complications, such as umbilical cord prolapse /compression, which can cause severe birth asphyxia [23]. 
Prolonged rupture of membrane was not significantly associated with birth asphyxia in contrary with study in Indonesia [30] indicated the prolonged rupture of membranes (>18 hours), was the most significant risk factor for birth asphyxia. This contradiction might be since the sample size of this previous study in Indonesia was small sample size (70 participants). The other reason might be due to setting difference between this study and the compared studies.

Parity had significantly associated with birth asphyxia. The odds of developing birth asphyxia among newborn of primparous mothers were 2.14 times more likely than newborns of multiparous. This finding is similar with study done in Aksum[31], Pakistan [19], Nigeria [17] and Kenya [23]. This might be due to the prim parous are often unknowing of the demands of pregnancy and often neglect regular follow up to antenatal care and necessitate of pregnancy check-up [12]. Furthermore, prim para mothers remain a high risk group due to factors which are more common among them such as biologic immaturity, a higher chances of cephalo-pelvic disproportion and prolonged fetal hypoxic and low pre pregnancy weight, all these factors might be influence the birth asphyxia [20]. In controversially, study in Dessie hospital [25] reported that parity had no significance association with birth asphyxia. This discrepancy might due to the decision of precision value of their study ( $p$ $\leq 0.2)$ which different from this study $(p<0.25)$ that may result to lose this important variable.

Low birth weight was an important determinant of birth asphyxia in this study. Newborns less than $2.5 \mathrm{~kg}$ were 4.43 times more likely to develop birth asphyxia than new born delivered with weight greater than $2.5 \mathrm{~kg}$. This finding is similar with the study done in Aksum[20], Gondar [25], Rwanda [20], Pakistan [15] and Kenya [23]. This might be due to the consequence of low birth weight was developed from maternal complication like hypertension, diabetes mellitus that present pre-conception or antepartum [12]. Low birth weight of newborn usually have pulmonary immaturity and limited respiratory muscle strength [32].

Preterm newborn was significantly associated with birth asphyxia. This study indicated that newborns with low gestational age were 5.77 times higher to develop birth asphyxia than their counterpart. This finding is consistent with the study findings in Pakistan [15] pointed that prematurity carried a substantially higher risk of developing birth asphyxia, with gestational age of lower than 37 weeks, increasing the risk of asphyxia. Study in Kenya [23] also reported that the low gestational age was more prone to birth asphyxia. This might be resulted from preterm babies face multiple morbidities including organ system, immaturity specially lung immaturities causing respiratory failure that cause to birth asphyxia [20]. However, study in Dessie hospital [33] and Gondar [25] evidenced that age of newborn no significantly associated with birth asphyxia. This discrepancy also might be due to the decision of $p$-value $(p \leq 0.2)$ which different from the study $(p<0.25)$ that might result to lose the important variable, measurement and observation bias.

\section{Conclusion}

Predictors were maternal and newborn related characteristics. Though, this predictors were mainly related to non-formal education, number of antenatal care follow up, prolonged duration of labour, non-cephalic fetal presentation, prim parous, preterm and low birth weight were the independent predictors of birth asphyxia.so, that improving ANC follow up, dedicating to give the correct, quick and accurate diagnosis and proper management of pathological disorders during pregnancy and delivery; more attention to low birth weights and preterm newborn at birth through providing good environment for delivery can reduce severe birth asphyxia. 


\section{Abbreviations And Acronyms}

ANC: Antenatal Care, AOR :Adjusted Odd Ratio, APH: Antepartum Hemorrhage, BA: Birth Asphyxia, Cl:

Confidence Interval, COR: Crude Odd Ratio, CP: Cerebral Palsy, CS: Caesarean Section, CSA: Central Statistical Agency, FMOH: Federal Ministry of Health, HIE: Hypoxic Ischemic Encephalopathy, HIV: Human Immunodeficiency Virus, MDG: Millennium Development Goals, MNCH: Maternal, Neonatal and Child Health, NICU: Neonatal Intensive Care Unit, OR: Odd Ratio, RHB: Regional Health Bureaus, SDGs: Sustainable Development Goals, SVD: Spontaneous Vaginal Delivery, UNICEF: United Nation Children's Fund, WHO: World Health Organization

\section{Declarations}

\section{Conflict of Interest}

The authors declare that there is no competing interest.

\section{Funding}

This research received no specific grant from any funding agency in the public, commercial or not-for-profit sectors.

\section{Author Contributions}

Conceived and designed by AF, FB and TF. AF and FB performed data analysis and interpreting of findings. TF prepares manuscript. All the authors read and approved the final manuscript.

\section{Author's Details:}

${ }^{1}$ Tarekegn Fakede (TF), (BSc, MSc in pediatrics and Child health): Department of Nursing, College of Health Science, Mettu University, Mettu, Ethiopia

${ }^{1}$ Abeya Fufa (AF), (BSc, MPH in RH): Department of Midwifery, College of health Science, Metu University, Metu, Ethiopia.

${ }^{2}$ Firomsa Bekele (FB), BSc in pharmacy, MSc in clinical Pharmacy): department of Pharmacy, College of Health Science, Mettu University, Mettu, Ethiopia.

\section{Acknowledgement}

First of all, I would like thank Jimma University, Institute of Health and population and family health department for financial support. My gratitude extends to study participants, hospital staffs, data collectors and supervisors.

\section{Ethical consideration}

Letter of ethical clearance was obtained from Institutional Review Board of Institute of Health, Jimma University and letter of cooperation from population and family health department. Informed consent was 
obtained after the purpose of the study was explained to participants. To ensure confidentiality the participants were informed that their data were coded and no need of writing their name.

\section{References}

1. Federal Democratic Republic of Ethiopia Ministery of Health, Integrated Management of Newborn and Childhood IIIness, Part 1. 2011. 1(Blended Learning Module for the Health Extension Programme): p. 116-7.

2. Roberto Antonucci, A.P., Maria Dolores Pilloni, Perinatal asphyxia in the term newborn. Journal of Pediatric and Neonatal Individualized Medicine. 2014;3(2): e030269, 2014 Oct 21. vol. 3 • n. 2 • 2014.

3. UNICEF, W., World Bank, UN-DESA Population Division, levels and trends in child mortality report 2018. book, 2018. book, 2018: p. 4-6.

4. GM, B.F.f., Population-based rates, timing, and causes of maternal deaths, stillbirths, and neonatal deaths in south Asia and sub-Saharan Africa: a multi-country prospective cohort study. Lancet Glob Health2018, 2018. Vol 6 December 2018: p. e1297.

5. UNICEF, Unicef for every child; U N IMaternal and Newborn Health Disparities inevery childEthiopia UNIm and NHD in. Ethiopia. book 2015: p. 4.

6. Antje Horsch, I.J., 2Leah Gilbert,1 Céline Favrod,1Juliane Schneider,1,3 Mathilde Morisod Harari,4Myriam Bickle Graz, Impact of perinatal asphyxia on parental mental health and bonding with the infant: a questionnaire survey of Swiss parents. BMJ Paediatrics Open, 2017: p. 1-2.

7. Olga Golubnitschaja, K.Y., Melanie Cebioglu, Micaela Morelli \& Mario Herrera-Marschitz, Birth asphyxia as the major complication in newborns: moving towards improved individual outcomes by prediction, targeted prevention and tailored medical care. EPMA Journal, 9 June 2011: p. 198-202.

8. Evelyn Mungyeh Mah, S.N.H.K.S., Andréas Chiabi; Mbassi Awa, Félicité Dongm, Mazou Ngou Temgoua lie Mbonda, Neurodevelopmental Problems in Children at 9 Months of Age Associated with Neonatal HypoxicIschemic Encephalopathy. Open Journal of Pediatrics, 2017: p. 98-108.

9. Secretary-General U, A., The global strategy for women's children's and adolescents' health (2016-2030). book, 2016: p. 6-14.

10. Chiabi A, N.S., Mah E, Nodem S, Mbuagbaw L, Mbonda E,Tchokoteu PF, Doh A. Iran J Child Neurol., Risk Factors for Birth Asphyxia in an Urban Health Facility in Cameroon. Iran J Child Neurol, 2013 Summer; 7(3). Vol 7 No 32013 Summer. p. 46- 54.

11. NDAYISENGA Theoneste, M.A., Factors Contributing to Birth Asphyxia as the Major Complication among Newborns Delivered at Gitwe District Hospital, Southern Province, Rwanda. International Journal of Public Health and Clinical Sciences, 2017;4(3). Vol 4: No 3: p. 142-51.

12. Bahubali Gane, V.B.B., Ramachandra Rao*, Nandakumar S*, Adhisivam B, Rojo Joy, Prasad P, Shruti S Antenatal and intrapartum risk factors for perinatal asphyxia A case control study Curr Pediatr Res, 2013;17(2): p. 119-22.

13. Tasew H, Z.M., Teklay G, Mariye T, Ayele E. BMC Res Risk factors of birth asphyxia among newborns in public hospitals of Central Zone, Tigray, Ethiopia 2018. Pediatric Health, Medicine and Therapeutics, 2018;11(1). 
14. Luo ZC, K.J. and Timing of birth and infant and early neonatal mortality in Sweden 1973-95: long itudinal birth register study. BMJ 2001;323(7325). 323: p. 1327-1327.

15. Nishant Yadav, S.D., Study of risk factors in children with birth asphyxia. International Journal of Contemporary Pediatrics, 2017 Mar;4(3). 4(2): p. 518-526.

16. Farhana Tabassum, A.R., Shabina Ariff, Sajid Soofi, Zulfiqar A. Bhutta Risk Factors Associated with Birth Asphyxia in Rural District Matiari, Pakistan A Case Control Study. International Journal of Clinical Medicine, 2014. 5: p. 1430-41.

17. West BA, O.P.J.p., Perinatal asphyxia in a specialist hospital in Port Harcourt, Nigeria.. Niger J Paed, 2013;40(3): p. 206-10.

18. Kaye., D., Antenatal and intrapartum risk factors for birth asphyxia among emergen cy 35 obstetric referrals in Mulago Hospital, Kampala, Uganda. East African medical journal., 2003. Vol. 80: p. 140-3.

19. Hafiz Muhammad Aslam Shafaq Saleem, R.A., Umair lqbal, Sehrish Muhammad Saleem, Muhammad Waqas Abid Shaikh and Nazish Shahid, Risk factors of birth asphyxia. Italian journal pediatrics, 2014: p. $1-9$.

20. Ala'a Hashim Tawfeeq, A.A., Assim Khalid Birth asphyxia in fullterm neonates in Basra maternity and children hospital. International Journal of Current Research, 2018. 6(09): p. 8887-8892.

21. Ige Olukemi Omowumi (FW ACP), A.R.O.M., Ekere Isylma Adannia (MBBS), T oma Bose O (FW ACP), Risk factors and mortality rate of severely asphyxiated neonates in a tertiary centre in north-central Nigeria. Jos J Med., 2013;7(1): p. 10-4.

22. Federal Democratic Republic of Ethiopia Ministery of Health, Integrated Management of Newborn and Childhood IIIness part 2. book, 2012.

23. Erick Kibai, D.V., and John Arud perinatal risk factors associated with birth asphyxia among term neonates at county referral hospita, Kenya. International Journal of Advanced Research., 2017: p. 5(7)10-20.

24. Anne CC Lee, M., MPH, Luke C. Mullany, PhD, James M. Tielsch, PhD, Joanne Katz, ScD, Subarna K. Khatry, MBBS, Steven C. LeClerq, MPH, Ramesh K. Adhikari, MD Shardaram R. Shrestha, MPH, and Gary L. Darmstadt, MD, Risk Factors for Neonatal Mortality Due to Birth Asphyxia in Southern Nepal: A Prospective, Community-Based Cohort Study. NIH Public Access, 2008.

25. Wosenu L, W.A., Teshome DF, Gelagay AA Determinants of birth asphyxia among live birth newborns in University of Gondar referral hospital, northwest Ethiopia A case-control study. PLoS One, 2018;13(9).

26. Tewesa E, C.E., Majamanda MD, Maluwa A, Chimwaza A Associative Factors for Birth Asphyxia at Queen Elizabeth Central Hospital-Malawi. AJ Biosci Med, 2017;05(05): p. 22-31.

27. Chayasak Pitsawong MD, P.P.M., Risk Factors Associated with Bir th Asphyxia in Phramongkutklao Hospital. Thai Journal of Obstetrics and Gynaecology, 2011;19(19). vol. 19. No 4: p. 165-171

28. McGuire, W., Child health Perinatal asphyxia. BMJ, 2007.

29. Rehana Majeed, Y.M., Farrukh Majeed, Naheed Parveen Shaikh, Uzma DM Rajar, RISK FACTORS OF BIRTH ASPHYXIA. J Ayub Med Coll Abbottabad 2007; 19(3).

30. Kardana, I., Risk factors of perinatal asphyxia in the term newborn at sanglah general hospital, baliindonesia. Bali Medical Journal (Bali Med J) 2016. Volume 5, Number 1: 175-178: p. 5(1) 175-8. 
31. Hagos Tasew, M.Z., Girmay Teklay, Teklewoini Mariye and Ebud Ayele, isk factors of birth asphyxia among newborns in public hospitals of Central Zone, Tigray, Ethiopia 2018. BMC Research Notes, 2018: p. 11:496.

32. MT., U., RISK FACTORS FOR BIRTH ASPHYXIA Folia Medica Indones, 2011;47(4)211-4.

33. Yohannes Kibret, G.H.a.K.A., Determinants of Birth-Asphyxia among Newborns in Dessie Town Hospitals, North-Central Ethiopia, 2018. Int J Sex Health Repro Health, 2018. 1(1): p. 1-12.

\section{Tables}

Table 1: Socio demographic characteristics of mothers who delivered at llu Aba Bor, Public Hospitals, Ethiopia, 2019

\begin{tabular}{lllll} 
& & Cases & Controls & Total \\
Variable & Category & $\mathrm{n}=103(\%)$ & $\mathrm{n}=\mathbf{2 0 5}(\%)$ & $\mathrm{n}=\mathbf{3 0 8 ( \% )}$ \\
\hline Age in years & 18-29 years & $58(56.31)$ & $87(42.44)$ & $145(47.08)$ \\
& $<18$ years & $18(17.48)$ & $38(18.54)$ & $56(18.18)$ \\
& $\geq 30$ years & $27(26.21)$ & $80(39.02)$ & $107(34.74)$ \\
\hline Marital status & Married & $75(72.8 \%)$ & $143(69.8 \%)$ & $218(70.78)$ \\
& Unmarried & $28(27.2 \%)$ & $62(30.2 \%)$ & $90(29.22)$ \\
\hline Educational & Not educated & $29(28.16)$ & $34(16.59)$ & $63(20.45)$ \\
& Educated & $74(71.84)$ & $171(83.41)$ & $245(79.55)$ \\
\hline Occupation & Government employer & $85(82.52)$ & $158(77.07)$ & $243(78.90)$ \\
& Self-business & $18(17.48)$ & $47(22.93)$ & $65(21.10)$
\end{tabular}

Table 2: Past obstetrics characteristics of mothers who delivered at llu Aba Bor, in Public Hospitals, Ethiopia, 2019 


\begin{tabular}{|c|c|c|c|c|c|}
\hline \multirow[t]{2}{*}{ Variable } & \multirow{2}{*}{\multicolumn{2}{|c|}{ Category }} & Cases & Controls & Total \\
\hline & & & $n=103(\%)$ & $n=205(\%)$ & $\mathrm{N}=308(\%)$ \\
\hline \multirow{2}{*}{$\begin{array}{l}\text { Number of } \\
\text { ANC }\end{array}$} & \multicolumn{2}{|l|}{$>=4$} & $84(81.55)$ & 173(84.39) & $257(83.44)$ \\
\hline & \multicolumn{2}{|l|}{$<4$} & $\begin{array}{l}19 \\
(18.45)\end{array}$ & $32(15.61)$ & $51(16.56)$ \\
\hline \multirow[t]{2}{*}{ Parity } & \multirow[t]{2}{*}{ Multipara } & \multirow[t]{2}{*}{ Primipara } & $75(72.82)$ & $114(55.61)$ & $189(61.36)$ \\
\hline & & & $28(27.18)$ & $91(44.39)$ & 119(38.64) \\
\hline \multirow[t]{2}{*}{ Miscarriage } & \multicolumn{2}{|l|}{ Yes } & $15(14.56)$ & $16(7.80)$ & $31(10.06)$ \\
\hline & \multicolumn{2}{|l|}{ No } & $88(85.44)$ & $189(92.20)$ & $277(89.94)$ \\
\hline \multirow[t]{2}{*}{ Child loss } & \multicolumn{2}{|l|}{ Yes } & $13(12.62)$ & 17(8.29) & $30(9.74)$ \\
\hline & \multicolumn{2}{|l|}{ No } & $90(87.38)$ & 188(91.71) & $278(90.26)$ \\
\hline
\end{tabular}

Table 3: Intra-partum characteristics of mothers who delivered at llu Aba Bor, in Public Hospitals, Ethiopia, 2019

\begin{tabular}{lllll} 
Variable & Category & Cases & Controls & Total \\
& & $\mathbf{n = 1 0 3 ( \% )}$ & $\mathbf{n = 2 0 5 ( \% )}$ & $\mathbf{N}=\mathbf{3 0 8 ( \% )}$ \\
\hline Duration of labour & Normal Prolonged & $83(80.58)$ & $192(93.66)$ & $275(89.29)$ \\
& & $20(19.42)$ & $13(6.34)$ & $33(10.71)$ \\
\hline Mode of delivery & SVD & $56(54.37)$ & $166(80.98)$ & $222(72.08)$ \\
& CS & $17(16.50)$ & $11(5.37)$ & $28(9.09)$ \\
& Instrument & $30(29.13)$ & $28(13.65)$ & $58(18.83)$ \\
\hline Prolonged rupture of membrane & Yes & $10(9.7 \%)$ & $11(5.4 \%)$ & $21(6.82)$ \\
& No & $93(90.3 \%$ & $194(94.6 \%)$ & $297(93.18)$ \\
\hline Fetal presentation & Non-cephalic Cephalic & $17(16.51)$ & $11(5.37)$ & $28(9.09)$ \\
& & $86(83.49)$ & $194(94.63)$ & $280(90.91)$ \\
\hline Delivery outcome & Single & $98(95.15)$ & $201(98.05)$ & $299(97.08)$ \\
& Multiple & $5(4.85)$ & $4(1.95)$ & $9(2.92)$
\end{tabular}

Table 4: Medical characteristics of mothers who delivered at llu Aba Bor, in Public Hospitals, Ethiopia, 2019. 


\begin{tabular}{lllll} 
Variable & Category & $\begin{array}{l}\text { Cases } \\
\mathrm{n=103( \% )}\end{array}$ & $\begin{array}{l}\text { Controls } \\
\mathrm{n}=\mathbf{2 0 5}(\%)\end{array}$ & $\begin{array}{l}\text { Total } \\
\mathbf{N}=\mathbf{3 0 8}(\%)\end{array}$ \\
\hline Anemia & Yes & $11(10.68)$ & $14(6.83)$ & $25(8.12)$ \\
& No & $92(89.32)$ & $191(93.17)$ & $283(91.88)$ \\
\hline Hypertension of mothers & Yes & $9(8.73)$ & $4(1.95)$ & $13(4.22)$ \\
& No & $94(91.27)$ & $201(98.05)$ & $295(95.78)$ \\
\hline $\begin{array}{l}\text { Diabetics during } \\
\text { pregnancy }\end{array}$ & Yes & $7(6.80)$ & $3(1.46)$ & $10(3.25)$ \\
\hline & No & $96(93.20)$ & $202(98.54)$ & $298(97.75)$
\end{tabular}

Table5: Neonatal characteristics of newborn who delivered at llu Aba Bor, in Public Hospitals, Ethiopia, 2019.

\begin{tabular}{lllll} 
Variable & Category & Cases & Controls & Total \\
& & $\mathbf{n = 1 0 3 ( \% )}$ & $\mathbf{n = 2 0 5 ( \% )}$ & $\mathbf{N = 3 0 8 ( \% )}$ \\
\hline Gestational age & $<=37$ weeks >37weeks & $26(25.24)$ & $15(7.32)$ & $41(13.31)$ \\
& & $77(74.76)$ & $190(92.68)$ & $267(86.69)$ \\
\hline \multirow{2}{*}{ Sex of neonate } & Female & $37(35.92)$ & $93(45.37)$ & $130(42.21)$ \\
& Male & $66(64.08)$ & $112(54.63)$ & $178(57.79)$ \\
\hline Newborn weight in gram & $<=2500 \mathrm{~g}$ & $21(20.38)$ & $14(6.83)$ & $35(11.36)$ \\
& $>2500 \mathrm{~g}$ & $82(79.62)$ & $191(93.17)$ & $273(88.64)$
\end{tabular}

Table 6: Bivariate \&Multi-variable Logistic Regression Analysis of Birth Asphyxia at llu Aba Bor zone, in Public Hospitals, 2019

COR: Crude Odds Ratio, AOR: Adjusted Odds Ratio, Cl: Confidence Interval, 1: reference category, * $\mathrm{p}$ value < $.05, * *=$ p. value $<0.001$ 


\begin{tabular}{lllllll} 
Variable & Category & Cases & Controls & COR & AOR & $\begin{array}{l}\text { P- } \\
\text { Value }\end{array}$ \\
\hline $\begin{array}{l}\text { Maternal } \\
\text { educational } \\
\text { status }\end{array}$ & $\begin{array}{llll}\text { Not } \\
\text { educated }\end{array}$ & $29(28.2 \%)$ & $34(16.6 \%)$ & $1.97(1.32,3.67)$ & $\mathbf{2 . 4 4 ( 1 . 3 7 , 4 . 3 4 )}$ & $\mathbf{0 . 0 0 6 *}$ \\
& Educated & $74(71.8 \%)$ & $171(83.4 \%)$ & 1 & $\mathbf{1}$ & \\
& & & & & &
\end{tabular}

$\begin{array}{lllllll}\text { Age in years } & \begin{array}{l}18-30 \\ \text { years }\end{array} & 58(56.3 \%) & 87(42.4 \%) & 1 & 1 & \\ & <18 \text { years } & 18(17.5 \%) & 38(18.5 \%) & 0.71(0.37,1.37) & .93(.40,2.13) & 0.870 \\ \geq 30 \text { years } & 27(26.2 \%) & 80(39.1 \%) & 0.51(0.41,0.88) & .65(.27,1.18) & 0.252\end{array}$

\begin{tabular}{lllll}
\hline $\begin{array}{l}\text { Number of } \\
\text { ANC }\end{array}$ & $>=4$ & $84(81.6 \%)$ & $173(84.4 \%)$ & 1 \\
Follow up & $<4$ & 19 & $32(15.6 \%)$ & $1.22(.65,2.28)$ \\
& & $(18.4 \%)$ & &
\end{tabular}

\begin{tabular}{lllllll}
\hline $\begin{array}{l}\text { Duration of } \\
\text { labour }\end{array}$ & Normal & 83(51.5\%) & $189(93.7 \%)$ & 1 & $\mathbf{1}$ & \\
& Prolonged & $20(48.5 \%)$ & $13(6.3 \%)$ & $3.50(0.13,0.59)$ & $\mathbf{4 . 1 2 ( 1 . 7 9 , 9 . 4 9 )}$ & $\mathbf{0 . 0 0 1 *}$
\end{tabular}

\begin{tabular}{lllllll}
\hline $\begin{array}{l}\text { Fetal } \\
\text { presentation }\end{array}$ & $\begin{array}{l}\text { Non- } \\
\text { cephalic } \\
\text { Cephalic }\end{array}$ & $\mathbf{1 7}(16.5 \%)$ & $\mathbf{1 1}(4.5 \%)$ & $3.49(1.57,7.75)$ & $\mathbf{4 . 3 5}(\mathbf{1 . 7 7 , 1 0 . 6 7 )})$ & $\mathbf{0 . 0 0 1 *}$ \\
\hline $\begin{array}{l}\text { Mode of } \\
\text { delivery }\end{array}$ & SVD & $56(54.4 \%)$ & $166(80.0 \%)$ & 1 & $\mathbf{1}$ & \\
& CS & $17(16.5 \%)$ & $11(4.5 \%)$ & $4.58(2.04,10.00)$ & $1.79(.87,4.69)$ & 0.232 \\
& Instrument & $30(29.1 \%)$ & $28(13.7 \%)$ & $3.18(1.75,5.88)$ & $1.47(.62,3.45)$ & 0.383 \\
\hline $\begin{array}{l}\text { Prolonged } \\
\text { rupture of } \\
\text { membrane }\end{array}$ & Yes & $10(9.7 \%)$ & $11(5.4 \%)$ & $1.9(0.78,4.62)$ & $1.02(0.28,3.70)$ & 0.970 \\
\hline Parity & Multipara & $28(27.2 \%)$ & $91(44.4 \%)$ & 1 & 1 & \\
& Primipara & $75(72.8 \%)$ & $114(55.6 \%)$ & $2.14(1.28,3.58)$ & $\mathbf{2 . 1 4 ( 1 . 2 0 , 3 . 8 3 )}$ & $\mathbf{0 . 0 1 0 *}$
\end{tabular}

\begin{tabular}{|c|c|c|c|c|c|c|}
\hline \multirow[t]{2}{*}{ Hypertension } & Yes & $9(8.7 \%)$ & $4(2.0 \%)$ & $4.81(1.16,14.8)$ & $3.13(0.69,14.17)$ & 0.140 \\
\hline & No & $94(91.3 \%)$ & 201(98.0\%) & 1 & 1 & \\
\hline \multirow{2}{*}{$\begin{array}{l}\text { Gestational } \\
\text { age }\end{array}$} & \multirow{2}{*}{$\begin{array}{l}<=37 \text { weeks } \\
>37 \text { weeks }\end{array}$} & $26(20.4 \%)$ & $15(40.0 \%)$ & $4.07(2.15,8.51)$ & $5.77(2.62,12.69)$ & \multirow[t]{2}{*}{$0.000 * *$} \\
\hline & & $77(79.6 \%)$ & $181(60.0 \%)$ & 1 & 1 & \\
\hline
\end{tabular}


at delivery

Newborn

weight in

gram
$<=2500 \mathrm{~g}$

$21(20.4 \%)$

82(79.6\%)
$14(6.8 \%)$

$191(93.2 \%)$
$3.49(1.69,7.21)$

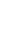

4.43(1.94,10.13) 0.000 * 1 